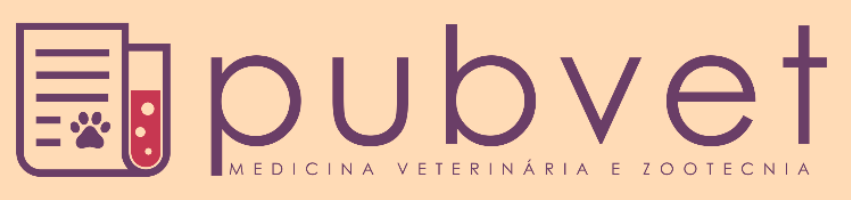

https://doi.org/10.31533/pubvet.v15n11a969.1-8

\title{
Identificação de pontos críticos relacionados com o bem-estar dos animais em leilões
}

\author{
Elivania de Sousa Lopes ${ }^{1}$, Eduardo Godoi Diniz ${ }^{1} \bullet$, Franciely de Oliveira $\operatorname{Costa}^{2} \odot \mathbb{D}$, Monique \\ Valéria de Lima Carvalhal ${ }^{3,4 * \bullet}$ (D)
}

${ }^{I}$ Discentes da Faculdade de Ensino Superior da Amazônia Reunida - Fesar. Redenção -PA Brasil.

${ }^{2}$ Docente do Centro Universitário Dr. Leão Sampaio - Unileão. Juazeiro do Norte-CA, Brasil.

${ }^{3}$ Docente da Faculdade de Ensino Superior da Amazônia Reunida - Fesar. Redenção -PA Brasil.

${ }^{4}$ Universidade Federal Rural da Amazônia-UFRA-Belém-PA Brasil.

*Autor para correspondência, E-mail: monique.carvalhal@ufra.edu.br

Resumo. O agronegócio Brasileiro a cada ano vem mostrando mais a sua importância no giro da economia do país, gerando empregos e renda em diversos setores, sendo o mercado leiloeiro um deles, pois desempenha um importante papel na esfera comercial. A comercialização de animais durante leilões levanta diversos questionamentos em relação ao bem-estar animal. Com base nessa temática, objetivou-se por meio dessa pesquisa identificar a percepção de pessoas participantes de leilões com relação ao bem-estar dos animais leiloados. $\mathrm{Na}$ pesquisa foram entrevistadas 91 pessoas que já participaram de leilões de animais, utilizando-se um formulário online com 17 questões, sendo que as primeiras estavam relacionadas a informações dos participantes, como cidade e estado de moradia, tipo de participação durante os leilões. As demais questões estavam relacionadas com situações que os animais enfrentam durante os leilões e questionavam aos participantes se concordavam com as afirmações. Os resultados foram tabulados e organizados em planilhas para fins de avaliação da coerência das análises estatísticas descritivas e a frequência de respostas foi contabilizada em cada item relacionado às perguntas analisadas. Concluiu-se que as pessoas envolvidas em leilões consideraram que aspectos relacionados à nutrição, saúde, comportamento e ambiente podem influenciar no bem-estar dos animais participantes.

Palavras chave: Comercialização, manejo, percepção

\section{Identification of critical points related to the welfare of animals in auction}

\begin{abstract}
The Brazilian agribusiness has been showing, annual, its importance in the country's economy, creating jobs and earnings in several sectors, and the auction market is one of them, cus it plays an important role in the commercial field. The animal's commercialization during auctions raises several questions in relation to animal welfare. Besed on this theme, the purpose of this research was to identify the perception of people participating in auctions regarding the auctioned animals' welfare. In the research, 91 people who have participated in animal auctions were interviewed, using an online survey contain 17 questions, the first of which were related to information from the participants, like city and dwelling state, type of participation during the auctions. The other questions were related to situations that animals used to face during auctions and asked the participants if they agreed with the statements. The results were tabulated and organized in spread sheet for the purpose of evaluating the coherence of descriptive statistical analyses, the frequency of responses was counted in each item related to the analyzed questions. So, the conclude was that people involved in auctions considered that aspects related to nutrition, health, behavior and environment can influence the welfare of participating animals.
\end{abstract}

Keywords: Commercialization, management, perception 


\section{Introdução}

Para enfrentar os desafios atuais relacionados à produção de animais é necessário desenvolver novas técnicas de manejo baseadas nos princípios de sustentabilidade, incluindo os princípios éticos relacionados à promoção do bem-estar dos animais (Broom \& Molento, 2004). Uma prática realizada com animais é o leilão, que constitui uma das mais importantes formas de comercialização de animais no país (Silva \& Santos, 2020). A dinâmica do leilão funciona assim; vendedores e compradores se reúnem em um mesmo ambiente, sendo os animais expostos individualmente ou em lotes e atribuindose lances sucessivos, onde o último lance permite a aquisição do lote/animal desejado (Costa et al., 2019). Essa prática de comercialização de animais é tradicionalmente realizada em nosso país e não há como negar que se tornou um evento comum e vantajoso do ponto de vista financeiro, desempenhando uma importante função na esfera comercial. As análises econômicas, principalmente as que envolvem a lucratividade, são o foco do sistema. No entanto, é importante também avaliar todos os aspectos que podem prejudicar o bem-estar dos animais e, consequentemente, a imagem dos leilões perante o público (Martins \& Pieruzzi, 2011).

Quando avaliamos os riscos aos quais os animais estão submetidos podemos expandir o conhecimento sobre as estratégias adaptativas dos animais e então realizar mudanças no manejo, de forma a adequar recomendações técnicas às necessidades da espécie (Broom \& Fraser, 2010). Raramente é levado em consideração o quanto se deixa de ganhar em sistemas onde os animais enfrentam dificuldades para se adaptar a ambientes que não atendem às suas necessidades físicas, comportamentais e psicológicas. Quando submetidos a um ambiente e/ou situação desafiadora, as tentativas dos animais para se adaptarem resultam em custo biológico e consequente risco de comprometimento nos índices produtivos. De acordo com Mellor \& Reid (2015), existem cinco domínios do bem-estar animal, sendo quatro domínios físicos (Nutrição, Ambiente, Saúde e Comportamento) e um domínio mental (Estado Mental), sendo considerado alto grau de bem-estar quando o animal está em estado de boa nutrição, saúde física e mental, confortável, seguro, tendo comportamentos naturais, com ausência de dor, medo ou angústia.

Além da importância econômica, temos que levar em conta os aspectos éticos que envolvem o manejo de animais, principalmente nas sociedades onde sustentabilidade e ética são o centro das discussões políticas e públicas sobre as práticas realizadas com os animais (Carenzi \& Verga, 2009). É evidente que o bem-estar animal vem se tornando cada vez mais importante dentro do cenário da produção e, qualquer mudança nesse panorama será possível a partir da demanda dos consumidores.

A falta de informação sobre a percepção da sociedade com relação aos animais utilizados em leilões é um entrave para que sejam realizadas melhorias nas práticas desenvolvidas. Portanto, é fundamental conhecer a percepção e atitude da sociedade diretamente envolvida com leilões sobre o bem-estar dos animais durante o evento. Desta maneira, o objetivo desta pesquisa foi identificar a percepção de pessoas participantes de leilões com relação ao bem-estar dos animais leiloados.

\section{Material e métodos}

No intuito de compreender a percepção das pessoas com relação ao bem-estar dos animais levados aos leilões foi realizada uma pesquisa qualitativa, utilizando um formulário online na plataforma Google Forms. O banco de questões foi criado com base na rotina e manejos aos quais os animais são submetidos durante os leilões, focando nos cinco domínios descritos anteriormente, são eles: "Nutrição", "Ambiente", "Saúde", "Comportamento" e "Estado mental". A aplicação de questionários é uma metodologia bastante utilizada para o recolhimento de informações diversas da população, obtendo respostas rápidas e de precisão, garantindo anonimato ao entrevistado o que reflete em uma maior liberdade para responder.

Durante a aplicação do questionário cada participante recebeu uma breve explicação sobre a temática da pesquisa. A pesquisa continha 17 questões, sendo que as primeiras estavam relacionadas a informações dos participantes, como cidade e estado de moradia, tipo de participação durante os leilões (comprador, vendedor, visitante, organizador, manejador) e envolvimento com a área das ciências agrárias (estudante, profissional, técnico, administrador de fazendas). As demais questões estavam relacionadas com situações que os animais enfrentam durante os leilões e questionavam aos 
participantes se concordavam com a afirmação sempre, às vezes, na maioria das vezes não, nunca ou não sei responder. Por exemplo: "No momento do embarque nas fazendas e desembarque no local do leilão, a forma como os animais são manejados pode causar algum problema?". As últimas questões foram dissertativas, possibilitando aos participantes descreverem experiências que tiveram durante leilões.

Após a coleta das respostas de todos os participantes foi gerada uma planilha no Excel para organizar os dados coletados. Em seguida, os resultados foram tabulados e organizados em planilhas para fins de avaliação da coerência das análises estatísticas descritivas e a frequência de respostas foi contabilizada em cada item relacionado às perguntas analisadas. $O$ teste utilizado para verificar a normalidade dos dados de todos os atributos avaliados foi o Shapiro-Wilk. Para comparar as proporções de respostas em cada possibilidade de resposta ( $\mathrm{sim}$, sempre, às vezes, na maioria das vezes não, nunca, não sei responder) foi utilizado o teste do Qui-quadrado, ao nível de significância de 5\%. O gráfico Wordcloud foi elaborado por meio do site wordart.com.

\section{Resultados e discussão}

Para avaliar a percepção das pessoas que participam dos leilões em relação aos pontos críticos que envolvem o bem-estar dos animais foram entrevistadas 91 pessoas que já participaram de leilões de animais. $\mathrm{O}$ tipo de participação (função) e/ou envolvimento das pessoas com os leilões de animais e a frequência de acordo com os respondentes foram apresentadas na Tabela 1.

Tabela 1. Frequência e porcentagem $(\%)$ de respondentes em relação à modalidade de participação nos leilões $(\mathrm{n}=91)$.

\begin{tabular}{lcc}
\hline Modalidade de participação & Frequência & Porcentagem $(\%)$ \\
\hline Visitante & 54 & 59,34 \\
Vendedor de animais & 5 & 5,49 \\
Comprador de animais & 16 & 17,59 \\
Trabalhou diretamente no manejo dos animais & 3 & 3,30 \\
Trabalhou na organização do leilão & 10 & 10,98 \\
Outras opções & 3 & 3,30 \\
\hline
\end{tabular}

*P valor $=<.0001$ entre as frequências observadas.

É possível observar que a maior parte dos participantes é de visitantes, tendo percentual de 59,34\%. $\mathrm{O}$ segundo maior número de participantes foi na modalidade de comprador de animais, que possuem um papel essencial na manutenção dos leilões. Eles definem os animais a serem comprados considerando aspectos como genética, aprumo, cor, peso, idade, histórico de desempenho reprodutivo e preço. É o comprador quem seleciona o animal de maior relevância para seus objetivos produtivos, focando também em uma negociação economicamente viável. Dessa maneira, ele também poderia escolher os animais com base em critérios relacionados ao grau de bem-estar no momento da compra. Para Franco et al. (2018) os objetivos econômicos podem ser compatíveis com melhores padrões de bem-estar na produção animal quando o consumidor (em leilões no papel do comprador) estiver apto.

A relação das pessoas participantes dos leilões com a agropecuária é um fator que pode influenciar na sua percepção com relação ao bem-estar dos animais envolvidos. Na Tabela 2 são descritas as frequências e porcentagens dos respondentes em relação à área técnica.

Tabela 2. Frequência e porcentagem de respondentes em relação ao envolvimento técnico com a área agropecuária $(\mathrm{n}=91)$.

\begin{tabular}{lcc}
\hline Relação com a área técnica & Frequência & Porcentagem $(\%)$ \\
\hline Estudante de curso de graduação das agrárias & 19 & 20,88 \\
Profissional técnico da área & 38 & 41,76 \\
Trabalhador de propriedade rural & 1 & 1,10 \\
Administrador ou dono de propriedade rural & 15 & 16,48 \\
Criador de animais & 6 & 6,59 \\
Não tenho formação, mas tenho vivência na área rural; & 12 & 13,19 \\
\hline
\end{tabular}

* P valor $=<.0001$ entre as frequências observadas. 
Estar envolvido com a área técnica pode refletir na percepção das pessoas com relação ao bem-estar dos animais. O conhecimento prévio da ciência do bem-estar animal também pode influenciar nas atitudes da pessoa durante a participação nos leilões, por exemplo, o trabalhador pode adotar técnicas de manejo baseadas nas boas práticas de produção durante o manuseio dos animais. Além disso, uma visão mais técnica pode representar melhores ações para intervir quando necessário, evitando ou corrigindo ações inadequadas. Quando foram perguntados sobre considerar se o leilão pode prejudicar os animais de alguma forma, a maior parte dos respondentes $(43,98 \%)$ acredita que "às vezes" o leilão pode prejudicar o bem-estar dos animais. Outro resultado que chama atenção é a porcentagem de participantes que não sabem responder a esta questão (35\%), como mostra a Figura 1, apesar de todos os respondentes terem alguma relação com o meio rural.

Você considera que o leilão possa prejudicar os animais de alguma forma?

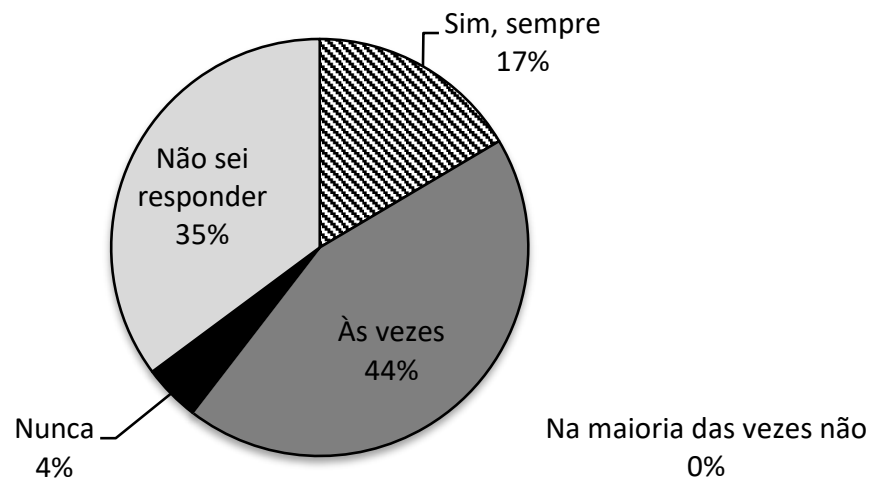

Figura 1. Porcentagem de respostas em relação à sétima pergunta do questionário $(\mathrm{n}=91) . * P$ valor $=<.0001$ entre as porcentagens observadas.

Os leilões constituem umas das mais importantes formas de comercialização dos animais. Inúmeros são os fatores que podem prejudicar o bem-estar dos animais no ambiente no qual estão inseridos e em leilões isso não é diferente. Dessa forma, o questionário foi elaborado com foco em alguns pontos que podem ser considerados críticos antes, durante ou depois de leilões. A percepção das pessoas com relação a cada ponto está apresentada no Quadro 1.

Ao participar dos leilões os animais passam pelo processo de embarque, transporte e desembarque e quando chegam ao local do leilão são expostos à estímulos que podem ocasionar medo ou estresse, comprometendo seu bem-estar e afetando sua qualidade de vida. Com a avaliação da percepção das pessoas envolvidas no evento podemos identificar os pontos mais críticos para determinarmos as tomadas de decisão.

A partir dos dados apresentados no Quadro 1, em relação ao questionamento do embarque e desembarque dos animais, 50,55\% das pessoas acreditam que "Às vezes" a forma como os animais são manejados pode causar algum problema. É sabido que o manejo influencia diretamente no bem-estar dos animais durante o embarque, transporte e desembarque. Nessas etapas existem vários fatores que podem afetar negativamente o animal. O estresse é decorrente da ausência de alimento e água, umidade elevada, velocidade do vento e quantidade de animais no mesmo espaço, desenvolvendo riscos à saúde animal, como respostas fisiológicas na forma de hipertermia, aumento da frequência cardíaca e respiratória (Costa et al., 2019). Dessa forma, as operações de embarque e desembarque dos animais devem ser conduzidas por pessoas treinadas que considerem aspectos do comportamento e da biologia dos animais (Grandin, 1997).

Sobre a importância da disponibilidade de água e alimento durante a permanência dos animais no local do leilão, 92,31\% das pessoas entrevistadas afirmaram que "Sim, sempre", e as demais pessoas $5,49 \%$ responderam que "Às vezes" é importante. Dando continuidade no tema da alimentação animal dentro dos leilões, $61,93 \%$ dos participantes da pesquisa afirmaram que "Sim, sempre" é importante para os animais manter a alimentação da fazenda de origem, e pequena porcentagem de pessoas $(2,20 \%)$ declarou que "Nunca". Ter alimento e água disponível é um critério importante considerado nos 
protocolos de avaliação do bem-estar animal (De Vries et al., 2011). Além disso, o estresse causado pela ausência de alimento ou mudança brusca na alimentação pode conduzir a perda de peso nos animais.

Quadro 1. Frequência e porcentagem de respostas em relação às perguntas do questionário relacionadas aos possíveis Pontos críticos para o bem-estar dos animais em leilões $(\mathrm{n}=91 ; P$ valor $=<.0001$ entre as porcentagens observadas em cada pergunta).

\begin{tabular}{|c|c|c|c|c|c|}
\hline \multirow[b]{2}{*}{ Perguntas } & \multicolumn{5}{|c|}{ Respostas } \\
\hline & Sim, sempre & Às vezes & $\begin{array}{l}\text { Na maioria das } \\
\text { vezes não }\end{array}$ & Nunca & $\begin{array}{l}\text { Não sei } \\
\text { responder }\end{array}$ \\
\hline $\begin{array}{l}\text { No momento do embarque nas fazendas e desembarque } \\
\text { no local do leilão, a forma como os animais são } \\
\text { manejados pode causar algum problema? }\end{array}$ & $\begin{array}{l}20,88 \\
(\mathrm{n}=19)\end{array}$ & $\begin{array}{l}50,55 \\
(n=46)\end{array}$ & $\begin{array}{l}26,37 \\
(n=24)\end{array}$ & $\begin{array}{l}2,20 \\
(n=2)\end{array}$ & $\begin{array}{c}\text { Não houve } \\
\text { respostas }\end{array}$ \\
\hline $\begin{array}{l}\text { Durante a permanência dos animais no local do leilão, } \\
\text { você considera que ter água e alimento disponível é } \\
\text { importante? }\end{array}$ & $\begin{array}{l}92,31 \\
(\mathrm{n}=84)\end{array}$ & $\begin{array}{l}5,49 \\
(n=5)\end{array}$ & $\begin{array}{l}\text { Não houve } \\
\text { respostas }\end{array}$ & $\begin{array}{l}\text { Não houve } \\
\text { respostas }\end{array}$ & $\begin{array}{l}2,20 \\
(\mathrm{n}=2)\end{array}$ \\
\hline $\begin{array}{l}\text { Durante a permanência dos animais no local do leilão, } \\
\text { vocês consideram que manter a alimentação da fazenda } \\
\text { de origem é importante para os animais? }\end{array}$ & $\begin{array}{c}61,93 \\
(n=60)\end{array}$ & $\begin{array}{l}20,88 \\
(n=19)\end{array}$ & $\begin{array}{l}9,89 \\
(n=9)\end{array}$ & $\begin{array}{l}2,20 \\
(n=2)\end{array}$ & $\begin{array}{l}1,10 \\
(\mathrm{n}=1)\end{array}$ \\
\hline $\begin{array}{l}\text { Durante a permanência dos animais no local do leilão, } \\
\text { você considera que misturar animais que não se } \\
\text { conhecem (animais de diferentes lotes e/ou locais de } \\
\text { origens) pode prejudicar os animais? }\end{array}$ & $\begin{array}{l}47,25 \\
(n=43)\end{array}$ & $\begin{array}{l}36,26 \\
(n=33)\end{array}$ & $\begin{array}{l}10,99 \\
(n=10)\end{array}$ & $\begin{array}{l}5,49 \\
(n=5)\end{array}$ & $\begin{array}{l}\text { Não houve } \\
\text { respostas }\end{array}$ \\
\hline $\begin{array}{l}\text { No momento em que o animal está sendo leiloado } \\
\text { (independente se ocorre em local aberto ou fechado), } \\
\text { você considera que o barulho (microfone, das } \\
\text { instalações...) pode prejudicar os animais? }\end{array}$ & $\begin{array}{l}40,66 \\
(n=37)\end{array}$ & $\begin{array}{l}31,87 \\
(\mathrm{n}=29)\end{array}$ & $\begin{array}{l}19,78 \\
(n=18)\end{array}$ & $\begin{array}{l}5,49 \\
(n=5)\end{array}$ & $\begin{array}{l}2,20 \\
(n=2)\end{array}$ \\
\hline $\begin{array}{l}\text { Você considera que leilões pode afetar a saúde (por } \\
\text { exemplo: doença, ferimento e lesão) dos animais de } \\
\text { forma geral? }\end{array}$ & $\begin{array}{l}13,19 \\
(n=12)\end{array}$ & $\begin{array}{l}50,55 \\
(\mathrm{n}=46)\end{array}$ & $\begin{array}{l}27,47 \\
(n=25)\end{array}$ & $\begin{array}{l}8,79 \\
(n=8)\end{array}$ & $\begin{array}{c}\text { Não houve } \\
\text { respostas }\end{array}$ \\
\hline $\begin{array}{l}\text { Você considera que o fluxo de pessoas desconhecidas } \\
\text { pelos animais no ambiente do leilão pode prejudicar os } \\
\text { animais? }\end{array}$ & $\begin{array}{l}27,47 \\
(n=25)\end{array}$ & $\begin{array}{l}39,56 \\
(\mathrm{n}=36)\end{array}$ & $\begin{array}{l}23,08 \\
(n=21)\end{array}$ & $\begin{array}{l}9,89 \\
(n=9)\end{array}$ & $\begin{array}{c}\text { Não houve } \\
\text { respostas }\end{array}$ \\
\hline $\begin{array}{l}\text { Você considera que o ambiente do leilão, de forma } \\
\text { geral, pode causar medo e/ou ansiedade aos animais? }\end{array}$ & $\begin{array}{l}47,25 \\
(n=43)\end{array}$ & $\begin{array}{l}35,16 \\
(\mathrm{n}=32)\end{array}$ & $\begin{array}{c}14,29 \\
(\mathrm{n}=13)\end{array}$ & $\begin{array}{l}2,20 \\
(n=2)\end{array}$ & $\begin{array}{l}1,10 \\
(n=1)\end{array}$ \\
\hline
\end{tabular}

Relacionado ao comportamento social, quando perguntados sobre a mistura de animais de diferentes lotes, a maior parte dos entrevistados $(47,25 \%)$ respondeu que "Sim, sempre" essa mistura pode prejudicar os animais. Realmente, misturar animais de diferentes lotes pode ser prejudicial aos animais, pois a hierarquia de dominância ou também conhecida como ordem social é considerada por Fraser (1982) como sendo o mais valioso integrante do comportamento social. A presença de uma hierarquia consolidada é de grande importância para estabelecer o bem-estar do rebanho (Fraser \& Broom, 1997; Fraser, 2009), minimizando as brigas dentro do grupo de animais e, consequentemente, reduzindo o estresse (Beilharz \& Zeeb, 1982). Sendo assim, quando misturamos lotes de animais desconhecidos, alteramos a estrutura social do grupo, causando a necessidade de restabelecimento da hierarquia por meio de disputas entre os indivíduos. Por isso, o mais indicado em leilões de animais é manter os animais em seus grupos de origem ou, ao menos, oferecendo espaço e recursos suficientes para todos os animais.

Com relação ao barulho quando o animal está sendo leiloado, cerca de 40,66\% dos respondentes concordaram que "Sim, sempre" este aspecto pode prejudicar o bem-estar dos animais, enquanto $31,87 \%$ consideraram que isso pode acontecer "Às vezes". De acordo com Grandin (1997), o barulho/ruído está na lista de "detalhes mínimos que assustam os animais". Relatando ainda que ruídos agudos como, por exemplo, alarmes de ré de caminhão, deixam bovinos muitos agitados. Nessa pesquisa não identificamos as espécies animais nas perguntas, mas especulamos que os respondentes consideraram principalmente bovinos e equinos, devido serem as espécies mais comumente vistas em leilões. Além do barulho já citado (alarmes de ré de caminhões), geralmente nos leilões os animais estão sujeitos a diversos estímulos sonoros como sons emitidos a partir de microfones, caixas acústicas, vozes, entre outros. Dessa forma, é importante avaliar os decibéis sonoros durante os leilões a fim de evitar estresse aos animais. 
Já nos quesitos saúde animal $(50,55 \%)$ e presença de pessoas desconhecidas $(39,56 \%)$, as respostas prevaleceram em que "Às vezes" podem prejudicar de alguma forma o bem-estar dos animais. Dessa forma, é evidente que os respondentes não conseguiram identificar uma relação direta da saúde do animal com as situações que ocorrem nos leilões. Os prejuízos na saúde do animal podem ocorrer de forma direta, quando sofrem lesões, por exemplo, e indireta. Levar os animais para o ambiente dos leilões implica na imposição de diversos fatores ambientais como: mudança na dieta, reagrupamento social, maior exposição a patógenos, exposição a condições climáticas e barulhos diversos (Mader, $\underline{2003}$ ) e frente a essa nova situação, sucessivas falhas em tentativas de se adaptar ao ambiente aumentam os custos biológicos para o animal, o que pode causar prejuízos ao seu estado geral de saúde.

A interação humano-animal é um dos critérios que deve ser considerado em qualquer avaliação do status de bem-estar dos animais e a presença de pessoas desconhecidas pode representar medo para os animais. Passillé et al. (1996) e Passillé \& Rushen (2006) descreveram que bezerros podem discriminar diferentes pessoas com base em experiências anteriores, o que pode levar os animais a desenvolverem medo de pessoas específicas, que lhes causaram algum tipo de sofrimento (Almeida et al., 2010; Andrioli et al., 2020). Dessa forma, nos leilões podemos incluir a possibilidade de os animais reconhecerem seres humanos específicos e essa capacidade influenciar a forma como os animais reagem a pessoas específicas. Além disso, nos leilões há a presença de visitantes que não possuem contato direto com animais, o que pode influenciar na forma como estas pessoas reagem aos animais e provocar situações que causem medo nos mesmos.

Ao questionar às pessoas se o leilão poderia causar medo e/ou ansiedade aos animais, a maior parte $(47,25 \%)$ afirmou que "Sim, sempre", e novamente apenas pequena porcentagem de pessoas $(2,20 \%)$ disse que "Nunca". Quando os animais estão sob situações que prejudicam seu bem-estar, eles experimentam sentimentos negativos como dor, medo, ansiedade, frustração e desesperança. Então, qualquer situação descrita anteriormente dita como prejudicial ao bem-estar dos animais pode implicar em medo. No entanto, é perceptível que nem todos os entrevistados associaram as situações relacionadas aos domínios físicos com o estado mental dos animais.

Como foi visto, a maior parte dos entrevistados identificaram que as situações citadas podem sim prejudicar o bem-estar dos animais, essa porcentagem de respostas pode estar relacionada com a formação dos entrevistados. A maioria é profissional técnico da área $(41,76 \%)$ ou estudante de curso de graduação das agrárias $(20,88 \%)$ (Tabela 2), isto confirma que o conhecimento é importante para identificar situações que coloquem em risco o bem-estar animal e, consequentemente, o desempenho animal.

É evidente que a sociedade moderna está cada vez mais atenta aos aspectos relacionados ao bemestar dos animais. Nossos resultados mostraram que as pessoas envolvidas em leilões afirmam estar cientes que o animal pode sofrer estresse ou lesões no transporte, que alimentação e água de qualidade são essenciais, que manter a mesma alimentação e o mesmo lote de origem pode evitar estresse e brigas e, de forma geral, que essas situações podem melhorar ou prejudicar o bem-estar dos animais participantes.

Ao final do questionário os entrevistados foram convidados a compartilhar de forma discursiva alguma experiência sobre leilões e também foram questionados se já haviam presenciado alguma situação que prejudicasse o bem-estar dos animais. Foram relatadas frases positivas como: "Nunca vi nenhuma situação estressante para os animais"; "Todos os animais são muito bem tratados, senão o vendedor não atingirá o objetivo do preço"; "Quase que 100\% dos leilões oferecem água e comida para os animais e existe um controle rigoroso para garantir o bem-estar dos animais. Controle esse que acontece também por parte dos visitantes". Por outro lado, também foram relatas experiências negativas com leilões, como: "Já vi acontecer algumas lesões em que animais tiveram que ser sacrificados."; "Algumas coisas como, por exemplo, muita gente, barulho, iluminação muito forte causam sofrimento, medo e tensão".

Também foram relatadas situações positivas e negativas na mesma resposta, como essa: "Já fui a leilões em que o manejo era bom, os funcionários tiveram treinamento para manejo racional e em leilões onde os animais entravam na pista sangrando de tanto apanhar. Na grande maioria o ambiente é 
desafiador para os animais". As palavras de maior constância observadas nas experiências dos participantes foram dispostas na Figura 2.

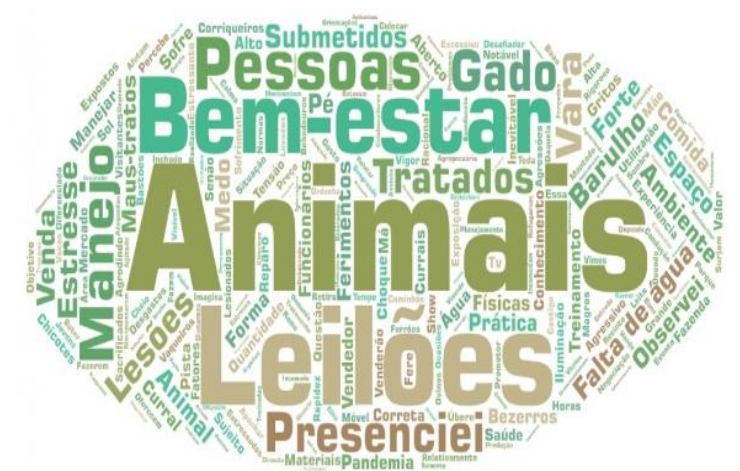

Figura 2. Word Cloud com as palavras mais observadas nas respostas discursivas do questionário.

O gráfico do tipo word cloud organiza as palavras de acordo com a sua importância, as palavras mais repetidas são apresentadas de maior tamanho. Assim é possível observar as palavras animais, bem-estar, leilões, pessoas, presenciei, tratados, submetidos, manejo, estresse; porém algumas palavras de maior peso também aparecem, como gritos, barulhos e experiência. A partir da análise das respostas e da imagem é possível notar que as pessoas envolvidas em leilões possuem experiências tanto negativas quanto positivas em relação ao bem-estar dos animais em leilões. Ainda que sejam relatadas situações que prejudiquem o grau de bem-estar dos animais em leilões, a oportunidade de escolha (principalmente relacionada a leilões que promovam melhores práticas) e acesso à informação para todas as pessoas envolvidas são cruciais para o fomento de estratégias que beneficiem a qualidade de vida dos animais.

\section{Considerações finais}

As pessoas envolvidas em leilões consideraram que aspectos relacionados à nutrição, saúde, comportamento e ambiente podem influenciar no bem-estar dos animais participantes. Além disso, foi evidenciado através dos relatos que já existem leilões que executam melhores práticas. Com base nas respostas obtidas, o problema chave parece estar relacionado principalmente às barreiras culturais e financeiras para a execução de melhores práticas. No entanto, não podemos desconsiderar todos os outros fatores que envolvem a ciência do bem-estar animal, por exemplo, questões éticas. É necessário ultrapassar esses obstáculos para que as pessoas envolvidas em leilões exerçam a preferência ética quando participarem. Dessa forma, sugerimos que o bem-estar dos animais participantes de leilões seja um critério a ser considerado durante a organização e/ou participação nesses eventos.

\section{Referências bibliográficas}

Almeida, P. A., Oliveira, J. R., \& Mantovani, M. M. (2010). Determinantes da interação homem-animal. PUBVET, 4(4), 144.

Andrioli, M., Carvalhal, M., Costa, F., \& Costa, M. P. (2020). Efeitos da interação humano-animal no bem-estar de ruminantes leiteiros: Uma revisão. Veterinária e Zootecnia, 27, 1-14. https://doi.org/10.35172/rvz.2020.v27.497.

Beilharz, R. G., \& Zeeb, K. (1982). Social dominance in dairy cattle. Applied Animal Ethology, 8(1-2), 79-97. https://doi.org/10.1016/0304-3762(82)90134-1.

Broom, D M, \& Molento, C. F. M. (2004). Animal welfare: concept and related issues-review. Archives of Veterinary Science, 9(2), 1-11.

Broom, Donald M, \& Fraser, A. F. (2010). Comportamento e bem-estar de animais domésticos. Editora Manole.

Carenzi, C., \& Verga, M. (2009). Animal welfare: review of the scientific concept and definition. Italian Journal of Animal Science, 8(1), 21-30.

Costa, P. T., Fernandes, T. A., Costa, R. T., Vaz, R. Z., Farias, P. P., Kröning, A. B., \& Rosa, P. P. (2019). Fatores que afetam a comercialização de bezerros em leilões na região Sul do Estado do Rio Grande 
do Sul, Brasil. Medicina Veterinária, 13(2), 244-250. https://doi.org/10.26605/medvet-v13n2-3080

De Vries, M., Bokkers, E. A. M., Dijkstra, T., van Schaik, G., \& De Boer, I. J. M. (2011). Invited review: Associations between variables of routine herd data and dairy cattle welfare indicators. Journal of Dairy Science, 94(7), 3213-3228. https://doi.org/10.3168/jds.2011-4169.

Franco, B. M. R., Sans, E. C. O., Schnaider, M. A., Soriano, V. S., \& Molento, C. F. M. (2018). Atitude de consumidores brasileiros sobre o bem-estar animal. Revista Acadêmica Ciência Animal, 16, 111. https://doi.org/10.7213/1981-4178.2018.161001.

Fraser, A. F. (1982). Comportamiento de los animales de granja. Zaragoza: Acribia, p.291.

Fraser, A. F., \& Broom, D. M. (1997). Farm animal behaviour and welfare (Issue Ed. 3). Cab International.

Fraser, D. (2009). Animal behaviour, animal welfare and the scientific study of affect. Applied Animal Behaviour Science, 118(3-4), 108-117. https://doi.org/http://dx.doi.org/10.1016/j.applanim.2009.02.020

Grandin, T. (1997). Assessment of stress during handling and transport. Journal of Animal Science, 75(1), 249-257. http://www.journalofanimalscience.org/content/75/1/249.abstract

Mader, T. L. (2003). Environmental stress in confined beef cattle. Journal of Animal Science, 81(14_suppl_2), E110-E119. https://doi.org/10.2527/2003.8114_suppl_2E110x.

Martins, M. F., \& Pieruzzi, P. A. P. (2011). Bem estar animal na bovinocultura leiteira. In M. V. D. Santos, L. F. P. Silva, F. P. Rennó, \& R. D. Albuquerque (Eds.), Novos desafios da pesquisa em nutrição e produção animal. VTN.

Mellor, D.J. \& Beausoleil, N.J. (2015). Extending the 'Five Domains' model for animal welfare assessment to incorporate positive welfare states. Animal Welfare 24, 241-253.

Passillé, A. M. B., \& Rushen, J. (2006). Calves' behaviour during nursing is affected by feeding motivation and milk availability. Applied Animal Behaviour Science, 101(3-4), 264-275. https://doi.org/http://dx.doi.org/10.1016/j.applanim.2006.02.007

Passillé, A. M., Rushen, J., Ladewig, J., \& Petherick, C. (1996). Dairy calves' discrimination of people based on previous handling. Journal of Animal Science, 74(5), 969-974.

Silva, J. A., \& Santos, F. R. N. (2020). A prática do leilão como proposta de mercado eficiente para a feira de gado: o caso de Alagoas. Revista de Economia e Sociologia Rural, 52(2). https://doi.org/10.1590/1806-9479.2020.177560.

Histórico do artigo:

Recebido: 7 de julho de 2021

Aprovado: 13 de agosto de 2021
Licenciamento: Este artigo é publicado na modalidade Acesso Aberto sob a licença Creative Commons Atribuição 4.0 (CC-BY 4.0), a qual permite uso irrestrito, distribuição, reprodução em qualquer meio, desde que o autor e a fonte sejam devidamente creditados. 